\title{
A DUPLA NATUREZA DO PROCESSO DE CONTROLE EXTERNO: SEGURANÇA JURÍDICA E EFETIVIDADE DAS POLÍTICAS PÚBLICAS DE DIREITOS HUMANOS
}

\section{THE DOUBLE NATURE OF THE EXTERNAL CONTROL PROCESS: LEGAL CERTAINTY AND EFFECTIVENESS OF PUBLIC HUMAN RIGHTS POLICIES}

\begin{abstract}
HENRIQUE RIBEIRO CARDOSO
Doutor em Direito, Estado e Cidadania (UGF/Rio), com Pós-doutorado em Democracia e Direitos Humanos (IGC - Universidade de Coimbra) e Pós-doutorado em Direitos Humanos e Desenvolvimento (PPGCJ/UFPB); Mestre em Direito, Estado e Cidadania (UGF/Rio); Professor do Programa de Pós-graduação da Universidade Federal de Sergipe (PRODIR/UFS) e do Programa de Pós-graduação da Universidade Tiradentes (PPGD/UNIT); Promotor de Justiça Titular da Fazenda Pública em Sergipe (MPSE); Membro da Academia Sergipana de Letras Jurídicas (ASLJ). Coordenador do Grupo de Pesquisa "Constitucionalismo, Cidadania e Concretização de Políticas Públicas" da Universidade Federal de Sergipe.
\end{abstract}

ISMAR DOS SANTOS VIANA Mestre em Direito. Especialista em Direito Administrativo. Especialista em "Combate à corrupção: prevenção e repressão aos desvios de recursos públicos". Especialista em Direito Educacional. Graduado em Direito. Graduado em Letras (Português/Inglês). Membro-fundador do Grupo de Pesquisa "Constitucionalismo, Cidadania e Concretização de Políticas Públicas" da Universidade Federal de Sergipe. Auditor de Controle Externo. Professor e Coordenador da Escola de Contas do Tribunal de Contas do Estado de Sergipe. Vice-presidente da Associação Nacional dos Auditores de Controle Externo dos Tribunais de Contas do Brasil. Advogado. Expresidente da Comissão de Direito Administrativo e Controle da Administração Pública 
da OAB/SE. Autor do Livro "Fundamentos do Processo de Controle Externo" (Lumen Juris, 2019).

\section{HÉLCIO KRONBERG}

Investigador, membro dos grupos de pesquisa Cidadania Empresarial no Século XXI Unicuritiba - Brasil, e integrante do grupo de Pesquisa Internacional - REDTH(Rede de Estudos em Direitos Huamanos e Transnacionalidade).

\section{RESUMO}

Objetivos: Este artigo objetiva analisar as reais causas do déficit de efetividade dos Tribunais de Contas. A Constituição Federal outorgou-lhes competências elencadas no art. 71, instituindo parâmetros para a edição de uma lei nacional para regulamentar o processo para a materialização do exercício de controle interno. O efeito da ausência legislativa tem levado à insegurança jurídica no controle das finanças públicas, de um lado, pela inobservância dos direitos e garantias processuais dos sujeitos que têm o dever de prestar contas e, do outro, pela dificuldade no alcance dos fins objetivados pelo modelo de federalismo cooperativo.

Metodologia: A metodologia deste estudo é dedutiva, associada a técnicas de pesquisa bibliográfica, por meio da revisão de doutrina, periódicos, artigos científicos e legislação. $O$ estudo foi estrategicamente dividido em uma pesquisa detalhada de temas que se relacionam estreitamente com o Direito do Trabalho.

Resultados: Como resultado da pesquisa, conclui-se que, embora a ausência de uma lei nacional do processo de controle externo seja uma das causas da assimetria entre os Tribunais de Contas do Brasil, em prejuízo à segurança jurídica e à higidez das finanças públicas, essa lacuna não constitui óbice intransponível à adoção de procedimentos uniformes para processar o exercício das competências institucionais estatuídas no art. 71 da Constituição de 988 , pautado na persecução do princípio da simetria constitucional previsto em seu art. 75 e na aplicação subsidiária dos demais ramos processuais.

Contribuições: Trazer à evidência da comunidade acadêmica que a ausência da legislação em tela não é uma trava que impede a existência de um controle externo, pois pode-se aplicar subsidiariamente os demais ramos processuais.

PALAVRAS-CHAVE: Controle; Devido Processo Legal; Segurança Jurídica; Direito Humanos; Política Pública. 
Objectives: This article aims to analyze the real causes of the deficit of effectiveness of the Courts of Audit. The Federal Constitution granted them the powers listed in art. 71 creating parameters for the edition of a national law to regulate the process for the materialization of the exercise of internal control. The effect of the legislative absence has led to legal insecurity in the control of public finances on the one hand, due to the non-observance of the procedural rights and guarantees of the subjects who have a 
duty to render accounts and, on the other hand, due to the difficulty in achieving the aims pursued by the model of cooperative federalism.

Methodology: The methodology of this study is deductive, associated with bibliographic research techniques, through the review of doctrine, periodicals, scientific articles and legislation. The study was strategically divided into a detailed survey of topics that are closely related to Procedural Law and Administrative Law.

Results: As a result of the research, it was concluded that, although the absence of a national law on the external control process is one of the causes of the asymmetry between the Brazilian Courts of Audit to the detriment of legal security and the soundness of public finances, this gap does not constitute an insurmountable obstacle to the adoption of uniform procedures to process the exercise of the institutional powers provided for in art. 71 of the Constitution of 1988, based on the pursuit of the principle of constitutional symmetry provided for in its art. 75 and in the subsidiary application of the other procedural laws.

Contributions: Bring to the evidence that the absence of the legislation in question is not a barrier that prevents the existence of an external control, since the other procedural branches can be applied alternatively.

KEYWORDS: control; due legal process; legal certainty; human rights; public policy.

\section{INTRODUÇÃO}

Trinta anos se passaram da promulgação da Constituição da República Federativa do Brasil de 1988 e a Administração Pública brasileira segue pautada pelo agir imediatista, sem planejamento de ações a longo prazo, permanecendo atada à ideia de que a máquina pública estatal é um fim em si mesma, e não meio para garantir a consecução dos serviços públicos essenciais ao cidadão, como se a eficiência administrativa e a efetividade das políticas públicas constituíssem ornamentos alocados na Constituição Democrática relegados a planos secundários de ações governamentais.

Essa atuação disfuncional da função administrativa na implementação de políticas públicas potencializa a demanda pela efetividade dos órgãos de controle externo, que precisam, a partir do regular exercício das competências elencadas no artigo 71 da CRFB/88, atuar na condição de indutores de efetividade dessas políticas, ao tempo em que são responsáveis por controlar as finanças públicas, a guarda de 
bens, valores e dinheiros públicos, assim como almejado pelo Legislador Constituinte originário.

Contudo, os Tribunais de Contas do Brasil, órgãos de controle externo da Administração Pública, também não têm correspondido adequadamente no exercício das competências que thes foram outorgadas, levando $83 \%$ dos brasileiros ao desconhecimento acerca da existência e do que fazem os Tribunais de Contas, conforme revelado em pesquisa do Instituto Brasileiro de Opinião Pública e Estatística (Ibope), realizada a pedido da Confederação Nacional da Indústria (CNI) e da Associação dos Membros dos Tribunais de Contas do Brasil (ATRICON).

E isso tem comprometido o regular desempenho da função de Controle Externo, que se reveste de dupla natureza: de um lado, decorre do direito de pedir contas, previsto no artigo 15 da Declaração dos Direitos do Homem e do Cidadão, de 1789, e, de outro, do dever de prestar contas, previsto no parágrafo único do artigo 70 da CRFB/88, de modo que as transgressões aos direitos de agentes incumbidos do dever de prestar contas são igualmente passíveis de controle e responsabilização, razão por que a regularidade no desempenho da função de controle constitui direito à fundamentalidade da regular atuação do próprio órgão de controle externo, que deve dispor de arranjos institucionais eficientes, que não elejam o punitivismo como fim a ser perseguido, mas que também não ofertem respostas suaves ou sanções brandas quando a gravidade das transgressões exigir rigor punitivo.

Nesse contexto, o artigo busca abordar as reais causas do deficit de efetividade institucional dos Tribunais de Contas, para, a partir disso, suscitar soluções aptas a corrigirem as disfunções atualmente existentes, de modo que os resultados das ações de controle possam garantir os fins para os quais esses órgãos foram criados.

Uma das premissas adotadas emerge da Declaração Universal dos Direitos Humanos de 1948, que erigiu a segurança a direito humano e fundamental, e enunciou, assim, a segurança jurídica na vertente voltada à confiança depositada dos cidadãos nas instituições republicanas, sobretudo as controladoras, impondo a elas um agir institucional adstrito aos parâmetros de regularidade de atuação, fim que também integra a meta 16.5 do Plano de Objetivos de Desenvolvimento Sustentável para 2030, da ONU. 
Essa regularidade de atuação depende, logo de início, da independência institucional e da independência funcional entre os integrantes dos órgãos de controle, conforme positivado no artigo 6º da Convenção de Mérida sobre corrupção, constituindo garantia indissociável da eficácia do combate ao crime organizado instalado nas instituições governamentais, preocupação reafirmada, também, na Resolução n. 1, de 16 de março de 2018, da Comissão Interamericana de Direitos Humanos, que se alicerçou no argumento de que a corrupção atinge os direitos humanos em sua integralidade, comprometendo as instituições democráticas e, por via de consequência, a governabilidade, agravando, assim, as desigualdades sociais.

É bem verdade que essas construções e análises não tratam de uma ciência exata, estática. $\mathrm{O}$ artigo se pauta no caráter dinâmico inerente aos Direitos Humanos, que, sem olvidar da existência de uma raiz mais ou menos estanque, é permeado em larga medida por interações e relações sociais, culturais, jurídicas e filosóficas, variáveis que se concretizam continuamente ao longo do tempo em fenômenos que se retroalimentam.

É que a dignidade da pessoa humana, na essência de sua acepção, não conseguirá ser alcançada mediante ações meramente paliativas ou que dependam de iniciativas de pessoas ou grupos alheios ao Estado, interagindo em um ambiente socialmente excludente. Em essência, ela somente pode ser lograda mediante Políticas de Estado viabilizadas ou fomentadas por instituições públicas e capazes de propiciar um contexto sustentável de inclusão social, de modo a atender minimamente as realidades e reduzir satisfatoriamente as disparidades, em contextos em que 0 poder público deve intervir e participar para materializar o ideal de um Estado Democrático de Direito.

Assim, para garantir o cumprimento da função de Controle Externo do Estado, a CRFB/1988 outorgou aos Tribunais de Contas competências constitucionais explícitas no artigo 71, dentre outras que decorrem dos poderes implícitos, que devem ser exercidas por meio de um processo justo e adequado, obedecidas as garantias do devido processo legal como condição de legitimidade decisória, argumento que se extrai dos artigos $5^{\circ}$, incisos LIV e LV, 73 c/c 96, I, "a" da CRFB/88, que devem ser interpretados conjuntamente, mormente porque o caput do artigo 73 é claro ao dispor que os Tribunais de Contas são integrados pelos julgadores e pelo quadro próprio de 
pessoal, necessariedade processual participativa que legitima e viabiliza o exercício das competências elencadas no artigo 71 da CRFB/88.

\section{DIREITO FUNDAMENTAL AO REGULAR EXERCíCIO DA FUNÇÃO DE CONTROLE}

Apesar de não taxativamente expresso na Constituição Federal de 1988 como direito fundamental, o controle é ínsito ao Estado Democrático de Direito, na medida em que se constitui instrumento limitador do próprio poder estatal, servindo como meio idôneo para evitar que abusos venham a ser cometidos em detrimento da regular atuação da Administração Pública, conclusão essa que se extrai do próprio artigo 5º, $\S 2^{\circ}$ da CRFB/88.

Ao oportunizar ao cidadão, no artigo $74, \S 2^{\circ}$, o direito de levar aos órgãos de controle notícias de fatos relacionados ao funcionamento do aparelho estatal, quis o Legislador Constituinte originário que a materialização do controle social, por meio da participação do cidadão no processo de controle de execução de políticas, pudesse contribuir com o alcance da eficácia na prestação dos serviços públicos postos à disposição da coletividade. E como a concretização do exercício do controle social depende da viabilização de meios para que o direito possa ser exercido, a própria Constituição impôs exclusivamente ao cidadão a condição de legitimado ativo para propor a ação popular, com vistas a anular atos lesivos ao patrimônio público.

É possível afirmar, também, que, de um lado, essa legitimação emerge do direito do cidadão de pedir contas de quem gere recursos públicos, previsto no artigo 15 da Declaração dos Direitos do Homem e do Cidadão, de 1789, e, de outro, do dever de prestar contas previsto no parágrafo único do artigo 70 da CRFB/88, que elegeu publicidade e a transparência como deveres corolários do dever de prestar contas, como meios de possibilitar ao cidadão, mantenedor do aparato estatal e beneficiário da prestação dos serviços públicos, o acesso às informações relacionadas às receitas e despesas públicas.

A disponibilização dessas informações, contudo, não supre o dever dos órgãos de controle de garantir a visibilidade delas, visto que o conteúdo técnico de 
que se revestem esses dados pode dificultar a interpretação deles e, por via de consequência, a compreensão do cidadão.

Atuações nessas bases permitem que esses órgãos sejam vistos como agentes indutores da efetividade das políticas públicas, conclusão que também se extrai do conceito de políticas públicas adotado por Maria Paula Dallari Bucci (2006, p.21-42), que, ao considerar como sendo um conjunto de ações articuladas, induz a existência das fases de formulação, execução e controle dessas políticas:

\footnotetext{
Política pública pode ser definida como um programa ou quadro de ação governamental, porque consiste num conjunto de medidas articuladas (coordenadas), cujo escopo é dar impulso, isto é, movimentar a máquina do governo, no sentido de realizar algum objetivo de ordem pública ou, na ótica dos juristas, concretizar um direito.
}

Para garantir o controle social e evitar a prática de abusos estatais, há, ainda, no plano infraconstitucional, a Lei n. 12.527, de 2011, intitulada Lei de acesso à informação, editada não apenas para regulamentar o inciso XXXIII do artigo 5 da CRFB/88, mas com o fim de viabilizar a instrumentalização do peticionamento a que alude o inciso XXXIV, alínea "a" do mesmo dispositivo constitucional, de cujo teor se extrai que a todos é assegurado o direito de peticionar aos Poderes Públicos contra ilegalidade ou abuso de poder.

Não se pode olvidar que a sobredita Lei não foi editada com o fim apenas de regulamentar o inciso II do $3^{\circ}$ do artigo 37 e o $2^{\circ}$ do artigo 216 da CRFB/88, mas para viabilizar que as denúncias e representações formuladas contra o exercício negligente ou abusivo de cargo, emprego ou função na Administração Pública, por exemplo, não ficassem dependendo tão somente da atuação dos agentes estatais, que, não raras vezes, deliberam por trilhar o caminho da inação, pautados exclusivamente por interesses pessoais, ou encontram óbices no modelo de estrutura estatal hierarquizada, que inviabiliza o processamento de demandas denunciativas que envolvam agentes públicos detentores de relevante poder de mando nessa estrutura, que nela ocupam posições de destaque.

A Lei n. 8.666/93, em seu artigo 113, $§ 1^{\circ}$, também cria um canal de acesso entre os Tribunais de Contas e o cidadão, ao prescrever que, na condição de licitante 
ou contratante, pode ele representar às Cortes de Contas, quando tiver conhecimento de irregularidades decorrentes de licitações e contratos públicos.

Nesse sentido, posicionando-se o cidadão na condição de detentor do direito fundamental ao controle, vê-se que o regular funcionamento dos Tribunais de Contas, de cuja ação dependerá, em certa medida, o atendimento das demandas do cidadão, também se insere no rol de direitos fundamentais implícitos.

Para além disso, integrando o devido processo legal o rol de direitos fundamentais, nos termos do artigo $5^{\circ}$, incisos LIV e LV, as disfuncionalidades na atuação de órgãos que exercem a função de controle, especialmente os órgãos de controle externo, que agem mediante processos, podem colocar em risco a proteção de direitos fundamentais, como honra, patrimônio e liberdade dos indivíduos.

Assim, esse agir institucional mediante processo e por meio do concurso necessário de ação de agentes que desempenham funções distintas é o que legitima as competências conferidas aos Tribunais de Contas pelo artigo 71 da CRFB/1988, entendimento que se extrai, também, da teoria da processualidade ampla, por via da qual se enuncia que as manifestações do poder público devem ser materializadas a partir de processos.

Esse caminho nos leva à conclusão de que a regularidade de atuação no desempenho da função de controle é passagem obrigatória para o alcance do direito fundamental à boa gestão pública, tendo em vista que aos órgãos de controle externo incumbem o monitoramento da execução de políticas públicas, aferindo, por expressa previsão constitucional e sempre pautado no respeito ao postulado do devido processo legal de controle externo, a eficiência e eficácia dessas políticas.

\section{TRIBUNAIS DE CONTAS NO BRASIL - ESTRUTURA, PROCESSO E DECISÕES DE CONTROLE EXTERNO - BALIZAMENTO CONSTITUCIONAL E REGULARIDADE DE ATUAÇÃO}

Como já anunciado, este artigo se volta à crítica à forma como se organizam internamente os Tribunais de Contas do Brasil, que, conforme se pretende demonstrar, não se amolda ao postulado do devido processo legal em sua 
completude, motivo pelo qual o panorama histórico a seguir delineado, avançando para além daquilo que recorrentemente trazem trabalhos acadêmicos que abordam tópicos desse jaez, não se propõe a limitar a abordagem às prerrogativas conferidas pelas constituições aos conselheiros e ministros das Cortes de Contas, buscando avançar na identificação de aspectos disfuncionais que permitam identificar as principais causas que comprometem a regularidade do desempenho da função de controle e da atuação desses órgãos de distinta envergadura constitucional incumbidos do cumprimento dessa função, e que, por via de consequência, comprometem a efetividade institucional, a segurança jurídica, portanto, no seu conceito amplo.

A Constituição de 1988, no Título IV, da organização dos Poderes, em seção própria do capítulo I, destinado ao Poder Legislativo, dispôs sobre a fiscalização contábil, financeira, orçamentária, operacional e patrimonial de todos os órgãos e poderes da República, conferindo os instrumentos para o exercício desse mister aos Tribunais de Contas, positivando expressamente, no artigo 71, as competências do órgão.

Não obstante a controversa divergência se os Tribunais de Contas exercem ou não jurisdição, o certo é que o artigo 71 da Bíblia Política brasileira elenca um extenso rol de competências constitucionais, o que, por si só, é o suficiente para se concluir acerca da incontroversa importância dos Tribunais de Contas para a manutenção do Estado Nacional e Democrático de Direito, que devem agir pautados na observância das normas de processo e das garantias processuais das partes, imposição que explicitamente se extrai do artigo 96, I, alínea "a", aplicado por força do artigo 73 da CRFB/1988, donde também se extrai a necessidade de uma estrutura orgânica interna capaz de garantir a imparcialidade de atuação desses órgãos de controle externo.

O Tribunal de Contas, conforme se extrai do texto constitucional, é uma instituição técnica, a quem foi conferida tratamento próprio, dentro da Constituição, tendo-Ihe sido atribuída a indispensável missão de emitir pareceres prévios, julgar contas dos administradores públicos, além das competências diretamente ligadas ao exercício fiscalizatório, que, ao fim, podem comprometer a capacidade eleitoral de agentes públicos, tornando-os inelegíveis, por força do artigo 1ํ, inciso I, alínea "g" da 
Lei Complementar n. 64/1990, alterada pela Lei Complementar n. 135, de 2010, e também podem, exemplificativamente, desencadear o surgimento de ações penais, ações de improbidade administrativa, a serem propostas pelos órgãos com legitimidade para tanto.

Da leitura dos artigos 70 a 75 da Constituição de 1988 já se extrai a fundamental importância dos Tribunais de Contas para o controle dos gastos públicos e, consequentemente, para o combate à prática de atos de corrupção, seja pela prevenção à ocorrência dos atos, seja pela instrumentalização das ações tendentes a responsabilizar os agentes a quem a prática desses atos é atribuída. É possível constatar que, na República brasileira, poucas instituições têm a sua razão de existência tão diretamente ligada à prevenção e ao combate à corrupção como as Cortes de Contas, tratando-se, portanto, de órgãos de controle externo da Administração Pública com atividade eminentemente fiscalizatória, de natureza independente, que auxilia a todos os poderes da federação e, ainda, a sociedade, esta destinatária final do trabalho desempenhado pelas Cortes de Contas.

Nesse panorama, vê-se que o elevado prestígio que vem sendo dispensado aos Tribunais de Contas, desde a Constituição de 1891, não se alicerça em outro motivo senão naquele em que, cada vez mais, torna-se imperiosa a prevenção à ocorrência de desvios de recursos públicos e a responsabilização daqueles que se propõem a gerir esses recursos, mas que, desviando dos fins a que originariamente se propuseram, terminam lesando o erário. Isso decorre, dentre outros fatores, da escassez e da má aplicabilidade desses recursos, o que exige a regular, efetiva e imparcial atuação dos órgãos de controle, a fim de que a população não fique desassistida de serviços públicos cuja essencialidade salta aos olhos de qualquer cidadão.

Diante dessa clarividente realidade, faz-se oportuna uma abordagem, a partir de uma análise da estrutura constitucional vigente, das razões pelas quais segmentos profissionais e acadêmicos vêm atribuindo a precariedade na execução de políticas públicas à omissão dos órgãos de controle, especificamente os Tribunais de Contas, no exercício dos seus misteres, sem qualquer repartição de responsabilidades, desnaturando, não raras vezes, a razão de existir de instituições republicanas indispensáveis à manutenção do Estado Nacional e Democrático de Direito. 


\subsection{ESTRUTURA DOS TRIBUNAIS DE CONTAS - CONFIGURAÇÃO CONSTITUCIONAL FALHA?}

A função de Controle Externo da Administração Pública não é um fim em si mesma, ela encontrando fundamento, sobretudo, na necessidade de limitar o arbítrio estatal, prestando-se a coibir excessos e desvios na gestão de recursos públicos, exigindo-se, assim, instituições de controle cujo funcionamento seja pautado em mecanismos de controle suficientemente capazes de aferir a eficácia das atividades controladas, por meio do ingresso, se necessário for, no campo da análise da legitimidade da ação estatal.

Speck (2000, p.154) aponta os mecanismos de controle sobre o êxito da atividade executiva como um dos elementos essenciais da administração moderna, coexistindo com o planejamento das atividades públicas e da implementação dessas políticas por meio de uma organização burocrática.

No Brasil, o modelo de instituição superior de controle adotado pelo Legislador Constituinte originário foi o de Tribunais de Contas, o que se depreende, inclusive, da parte final do artigo 71 , que, ao positivar que ao "Tribunal de Contas compete" e elencar as competências conferidas a esses órgãos - e não apenas a uma das funções que o integram -atrelou a materialização dessas competências à necessária colegialidade processual-decisória; bem como do artigo 73 c/c 96, I, "a", que, ao prescrever sobre a necessidade de observância das normas de processo e respeito às garantias processuais das partes, tratou do devido processo legal de controle externo; e, ainda, dos incisos II e VIII do artigo 71, ao dispor sobre o poder jurisdicional e sancionatório, características essas que se diferenciam do modelo de Controladoria ou Auditoria Geral, consoante já tratado em tópico próprio.

No que tange à estrutura e o funcionamento dos Tribunais de Contas, o Constituinte consolidou, no artigo 73, a existência de quadro próprio de pessoal, preestabelecendo que as Cortes de Contas exercem, no que couber, as atribuições previstas no artigo 96, que versa exatamente sobre a organização e o funcionamento dos Tribunais Judiciários.

Para compreender o sentido e o alcance do artigo 73, necessária se faz uma interpretação sistêmica, a começar pelo uso do termo integrado, cujo sentido outro 
não é senão o de combinação de partes ou etapas que funcionam de forma completa (DIClO, 2018), do que se extrai que os nove ministros e o quadro próprio de pessoal integram o Tribunal de Contas da União, composição conjunta, embora independente no plano processual, e é o que garante a regularidade no desempenho da função de Controle Externo desempenhada pelos Tribunais de Contas.

Ainda nessa exegese, pode-se concluir que, ao manter a imposição de quadro próprio de pessoal, expressão utilizada pelo Texto Constitucional exclusivamente para tratar do funcionamento dos Tribunais de Contas, quis o Legislador Constituinte que esse modelo de aparato orgânico-funcional não sofresse interferência, interna ou externa, evitando que agentes públicos sem vínculo institucional próprio com o órgão controlador, sem atribuição legal, portanto, viessem a realizar as inspeções e auditorias, competências conferidas pela CRFB/88 em juízo de privatividade aos Tribunais de Contas.

Isso porque, diferentemente do Poder Judiciário, cuja função típica e exclusiva é a de julgar - o que justifica a necessidade de estruturação orgânica em formato de secretarias auxiliares - os Tribunais de Contas concentram, num só órgão, as funções de investigar, acusar e julgar, razão pela qual o Constituinte foi taxativo quanto à necessidade de quadro próprio de pessoal para o desempenho das competências finalísticas de controle externo estatuídas no artigo 71 da $\mathrm{CF}$, num formato que garanta a observância do sistema acusatório não puro, pautado na independência plena das três funções processuais.

Não fosse essa a exegese consentânea com a lógica processual, teria o texto do artigo 73 adotado o mesmo termo usado para os Tribunais do Judiciário, limitandose a afirmar que o Tribunal de Contas da União seria composto por nove Ministros, teria sede no Distrito Federal, jurisdição em todo o território nacional, e exerceria, no que coubesse, as atribuições previstas no art. 96, que já dispõe sobre a organização e funcionamento do Poder Judiciário. Teria, portanto, sido silente quanto ao uso da expressão quadro próprio de pessoal, seguindo o princípio de hermenêutica jurídica, segundo o qual o texto legal não traz palavras inúteis.

Ocorre que, não obstante seja esse o figurino constitucional vigente, após trinta anos da promulgação da Constituição Democrática, a ausência de uma lei nacional de processo de controle externo e a manifesta assimetria constitucional entre 
os 33 Tribunais de Contas, em descompasso com o que almejou a Constituição Federal, em seu artigo 75 , constituem fator crítico para a eficácia da atuação dos Tribunais de Contas do Brasil no controle de bens, valores e dinheiros públicos, o que não relativiza a importância desses órgãos no contexto constitucional.

Isso porque, como já tratado em parágrafos precedentes, as Constituições brasileiras sempre guardaram espaço privilegiado para os Tribunais de Contas, dotando-os de instrumentos próprios para o cumprimento das competências constitucionais outorgadas, tudo com vistas a garantir que a função de Controle Externo da Administração Pública pudesse ser efetivamente desempenhada, possibilitando ao cidadão, a partir da regular atuação, o acesso às políticas públicas de Direitos Humanos.

Não é despiciendo rememorar que foi exatamente por erigir o cidadão à condição de sujeito de direitos que a Constituição de 1988 passou a ser tratada como Constituição cidadã, que alcança o dever de proteção dos cidadãos contra os arbítrios estatais, contra as transgressões aos seus direitos.

Nesse sentido, como não poderia ser diferente, ao tratar da fiscalização contábil, financeira e orçamentária, atribuindo tal mister aos Tribunais de Contas, positivou, no artigo 73 , que esses órgãos exerceriam, no que coubesse, as atribuições do artigo 96, que, dentre outras, impõe que o funcionamento dos órgãos administrativos e jurisdicionais deve observar as normas de processo e das garantias processuais das partes. Esse é o ponto no qual se fundam as críticas relacionadas à estrutura e funcionamento dos Tribunais de Contas no Brasil, em cujo elenco se incluem a ausência de uma lei orgânica nacional para os trinta e três tribunais de contas, composição do colegiado julgador integrada minoritariamente pelas carreiras técnicas, abrindo larga margem para o ingresso de cidadãos egressos da vida políticopartidária e que não detenham os notórios conhecimentos nas ciências elencadas no inciso III do $\S 1^{\circ}$ do art. 73 da CF, ausência de um conselho nacional de natureza correcional, à semelhança do Conselho Nacional do Ministério Público e Conselho Nacional de Justiça, inexistência de autonomia administrativa, orçamentária e financeira do Ministério Público que atua junto aos Tribunais de Contas, ausência de um código nacional de processo de controle externo, fixação de prazo para julgamento das contas presidenciais anuais pelo Congresso Nacional, e a própria omissão quanto 
à independência das três funções processuais, diferentemente do que ocorreu com a Constituição de 1967, que, ao positivar o §5o do artigo 73 da CF de 1967, prescrevendo que a função judicante seria desempenhada de ofício ou mediante provocação do Ministério Público ou das Auditorias Financeiras e Orçamentárias, reconheceu a delimitação das três funções, judicante, ministerial e auditorial.

Quanto à composição e ingresso do colegiado julgador, registre-se que, de 1891 a 1988, o poder de escolha dos membros recaía sobre o Presidente da República. Na Constituição Federal de 1988, contudo, esse poder de escolha passou a ser 1/3 pelo presidente da República e 2/3 pelo Congresso Nacional. Diferente da CF de 1967, a CRFB 1988 passou a exigir, além da idoneidade moral, a reputação ilibada, revelando, assim, a distinção conceitual dos requisitos, malgrado ainda seja recorrente o exercício da interpretação tratando como expressões sinônimas.

Assim, o problema não reside tão somente nos requisitos de escolha dos integrantes da função judicante, o problema também reside na ausência de observância dos critérios impostos como condição de ingresso, na benevolente e flexível interpretação que se tem dado aos requisitos, no sentido desvirtuado que se tem conferido às palavras, na intencional confusão que se faz, por vezes, entre reputação ilibada e presunção ou estado jurídico de inocência, na vagueza interpretativa que tem sido dada ao requisito da idoneidade moral, sobretudo porque de um julgador de contas deve-se esperar mais do que reputação ilibada, espera-se dele reputação inquestionável, na medida em que exercerá ele o controle de legitimidade dos atos públicos, ingressando, portanto, na análise da motivação decisória desses atos, que gozam da presunção de legitimidade.

Necessário se faz aclarar que os requisitos exigidos como condição de nomeação e posse no cargo de ministro ou conselheiro são mais rigorosos do que aqueles exigidos como condição de provimento do cargo de ministro do Supremo Tribunal Federal. Essa constatação, contudo, não tem o propósito de afirmar que a forma de composição e ingresso não precise ser reformulada. Aliás, as recorrentes críticas que partem de setores especializados apontam que essa disfunção coloca em risco a imparcialidade de atuação dos Tribunais de Contas, donde se extrai que a forma de composição precisa realmente ser revista, mas, apenas isso, reitere-se, não 
equacionará o deficit de efetividade institucional, embora possa relativizar o deficit de acreditação social.

Essa imperiosa necessidade de observância do preenchimento desses requisitos se deve, sobretudo, à possibilidade de reflexos da atuação dos Tribunais de Contas nos direitos subjetivos de terceiros, que podem, em razão da atuação das Cortes, tornarem-se réus em ações penais e de improbidade administrativa, terem comprometidos os seus direitos políticos, serem inabilitados para o exercício de funções públicas, além de tantas outras medidas gravosas e lesivas ao patrimônio, à honra e à imagem daqueles que se dispõem a gerir a coisa pública.

A instituição de um conselho nacional de natureza disciplinar poderia servir para corrigir eventuais disfunções decorrentes da composição do colegiado julgador estatuída na Lei Maior da República?

Como os conselhos correcionais atualmente existentes no Brasil são integrados majoritariamente por representantes dos órgãos e poderes sujeitos à correção, apesar da composição plural, um conselho nacional dos Tribunais de Contas, em razão da configuração vigente, poderia se constituir numa grande corregedoria nacional com os mesmos vícios e ausência de efetividade das existentes atualmente em alguns Tribunais de Contas, podendo, a depender da composição, é claro, ser mais uma instância com força capaz de legitimar a prática de atos passíveis de punição disciplinar do que efetivamente de repressão a desvios de conduta dos integrantes dessas instituições.

Como se propõe a evidenciar neste artigo, malgrado o atual figurino constitucional tenha aberto margem para as sobreditas disfunções, contribuindo para a ausência de efetividade institucional dos Tribunais de Contas, oportunizou meios, por outro lado, para que esses órgãos de controle externo pudessem cumprir as competências constitucionais estatuídas, em grande medida, no artigo 71, sem que para tanto viessem a ser objetos de descrédito institucional.

A via da simetria constitucional a que aduz o artigo 75 da CRFB/88 constitui um desses meios, na medida em que coloca o Tribunal de Contas da União como paradigma de estrutura e funcionamento para os Tribunais de Contas dos Estados e do Distrito Federal, bem como para os Tribunais e Conselhos de Contas dos Municípios, possibilitando a abertura de caminhos para a redução do atual deficit de 
efetividade institucional desses órgãos, conforme tem reiteradamente decidido o Supremo Tribunal Federal:

O art. 75, caput, da Constituição da República contempla comando expresso de espelhamento obrigatório, nos Estados, no Distrito Federal e nos Municípios, do modelo nela estabelecido de controle externo da higidez contábil, financeira e orçamentária dos atos administrativos, sendo materialmente inconstitucional a norma de regência da organização ou funcionamento de Tribunal de Contas estadual divorciada do modelo federal de controle externo das contas públicas (BRASIL, 2019).

Há, portanto, caminhos a serem percorridos para se chegar ao estabelecimento de um padrão mínimo de organização e funcionamento do Órgão de Fiscalização e Instrução processual dos 33 Tribunais de Contas, assegurando, por exemplo, a independência funcional do agente público que titulariza o desempenho das funções de fiscalização e instrução processual, finalísticas de controle externo, evitando, assim, que a ausência de isenção na instrução processual coloque em xeque o dever de imparcialidade que constitui corolário do devido processo legal, criando, ainda, condições institucionais para assegurar a uniformização desse órgão, em toda a Federação, o que ainda é um desafio no funcionamento de alguns Tribunais de Contas, garantindo que nas 33 Cortes de Contas em funcionamento no Brasil o dirigente máximo do órgão de fiscalização e instrução processual possa ser um auditor de controle externo concursado ${ }^{1}$, escolhido pelo presidente dessas Cortes, dentre os integrantes da respectiva carreira, a partir de critérios objetivos mínimos sobre as habilidades técnicas que deverão ser definidas numa lei orgânica nacional, por exemplo, assim como consolidado em Proposta de Emenda Constitucional que tramita no Senado Federal - PEC 40, de 2016.

Dessarte, para ser atingido o fim almejado pelo Legislador Constituinte originário, os Tribunais de Contas precisam ser reconhecidos como paradigmas de funcionamento da Administração Pública, como instituições cuja razão de existir se encontra diretamente ligada à proteção da coisa pública, motivo pelo qual parece se

\footnotetext{
1 Agente público concursado original e especificamente para o exercício de atividade exclusiva de Estado, de complexidade e responsabilidade de nível superior, relativas à titularidade das atividades indissociáveis e privativas de planejamento, coordenação, execução de auditorias, inspeções, instruções processuais e demais procedimentos de fiscalização e competências dos Tribunais de Contas - PEC 40/2016-SF.
} 
fazer necessária a adoção de ações concretas que possibilitem o equacionamento do deficit de legitimidade institucional que decorre do arranjo institucional vigente, que falhou em alguns aspectos, mas oportunizou caminhos para que esses órgãos controladores pudessem efetivamente cumprir a função de controle externo que the foi constitucionalmente outorgada, dentre os quais a simetria a que aduz o artigo 75 da CRFB/88.

É que modelos de funcionamento do órgão de instrução desse jaez, embora formalmente afastem a subordinação das unidades técnicas de auditoria aos julgadores, conselheiros e ministros, na prática, as tornam subordinadas e inteiramente deles dependentes, podendo servir para conferir aparência de legitimidade de instruções processuais, auditorias e inspeções nos órgãos e entidades jurisdicionados, colocando em risco de nulidade judicial as instruções realizadas sem a observância do princípio da independência técnico-funcional, que constitui direito subjetivo do gestor e de terceiros que mantêm vínculo com a Administração Pública, princípio que busca garantir, também, a proteção jurídica do corpo técnico que integra o quadro próprio de pessoal do órgão, que precisa agir com isenção, sem carga de sentimentalidade.

Assim, a ausência de independência, de fato e aparente, entre os integrantes dessas três funções processuais de controle externo remete ao sistema inquisitório, que, conforme tratado por Aury Lopes Júnior (2017, p.172), foi "desacreditado principalmente - por incidir em um erro psicológico: crer que uma mesma pessoa possa exercer funções tão antagônicas como investigar, acusar, defender e julgar."

A necessidade de independência do auditor, aliás, é objeto de tratamento próprio pelas Normas de Auditoria do Setor Público (NBASP 40), que, ao tratar do controle de qualidade das auditorias realizadas pelos Tribunais de Contas, preconiza que:

Os Tribunais de Contas devem garantir que todo trabalho seja objeto de revisão, preservada a independência da conclusão técnica do auditor, como forma de contribuir para a qualidade e promover a aprendizagem e 0 desenvolvimento dos seus servidores (IRB, 2015).

Aqui, diferentemente do Ministério Público de Contas, não há que se falar em autonomia do Órgão de Instrução, não se trata de buscar a separação do Órgão de 
Instrução da estrutura orgânica dos Tribunais de Contas, que detêm o poder de autogoverno para exercer a iniciativa privativa de encaminhar ao Poder Legislativo propostas orçamentárias, de criação de cargos e reajustes remuneratórios, dentre outras competências.

Isso posto, parece clarividente que modelos de funcionamento dos órgãos de fiscalização e instrução processual que não sejam pautados na independência plena entre as três funções processuais de controle externo caminham na contramão do sistema acusatório processual não puro, adotado pela CRFB/88, o que coloca diretamente em risco o dever de imparcialidade de autuação dos Tribunais de Contas.

\section{PROCESSO DE CONTROLE EXTERNO NOS TRIBUNAIS DE CONTAS: SEGURANÇA JURÍDICA DO GESTOR E DE QUEM MANTÉM VÍNCULO COM A ADMINISTRAÇÃO PÚBLICA}

O Supremo Tribunal Federal tem recorrentemente se pronunciado no sentido de considerar que o processo que tramita nos Tribunais de Contas não se confunde com o processo administrativo, sustentando-se no argumento de que o processo administrativo tem por finalidade própria concretizar a lei, ao passo que o processo de controle externo tem como fim controlar $o$ ato emanado a partir do processo administrativo, verificando se a lei foi respeitada e em quê medida. Trata-se, como consignado em diversos precedentes da Corte (BRASIL, 2001), de um processo de colorido quase-jurisdicional, que se encontra mais próximo do processo penal do que do processo civil, por razões como a indisponibilidade do interesse público e da verdade real, princípios que marcam a atuação processual penal e de processos de controle externo de responsabilização, ramos do direito processual punitivo.

Essa distinção processual - administrativo e controlador - é manifestada no entendimento trilhado pelo ministro Carlos Ayres Britto (2018):

[...] os processos instaurados pelos Tribunais de Contas têm sua própria ontologia. São processos de contas, e não processos parlamentares, nem judiciais, nem administrativos. Que não sejam processos parlamentares nem judiciais, já ficou anotado e até justificado (relembrando, apenas, que os Parlamentos decidem por critério de oportunidade e conveniência). Que também não sejam processos administrativos, basta evidenciar que as 


\begin{abstract}
Instituições de Contas não julgam da própria atividade externa corporis (quem assim procede são os órgãos administrativos), mas da atividade de outros órgãos, outros agentes públicos, outras pessoas, enfim. Sua atuação é consequência de uma precedente atuação (a administrativa), e não um proceder originário. E seu operar institucional não é propriamente um tirar competências da lei para agir, mas ver se quem tirou competências da lei para agir estava autorizado a fazê-lo e em quê medida.
\end{abstract}

Aliás, a natureza jurídica do processo que tramita nos Tribunais de Contas passou a ser mais claramente definida após a positivação trazida pela Lei n. 13.655, de 25 de abril de 2018, que, ao reconhecer a existência própria da esfera controladora, atrelando-a ao cumprimento de deveres inerentes ao ramo processual punitivo, como motivação, proporcionalidade, razoabilidade, segurança jurídica, reconheceu-se, por via de consequência, a figura do processo controlador, já denominado de "processo de controle externo" em Propostas de Emenda à Constituição que tramitam no Congresso Nacional (PEC 40/2016-SF, PEC 22/2017-SF, PEC 329/2013-CD), denominação adotada por este artigo.

Essas Propostas de Emendas à Constituição Federal contemplam a instituição de uma lei nacional de processo de controle externo, caminho que se fundamenta no artigo 24, I, passando pelo artigo 163, V, com redação dada pela EC 40/2003, que versa sobre a edição de lei complementar para dispor sobre fiscalização financeira da administração pública direta e indireta, numa exegese conjugada com o artigo 75 , que também sustenta a necessidade de uniformização de organização e procedimentos de fiscalização das finanças públicas, com vistas, ainda, por exemplo, ao alcance dos fins a que se propõe a regionalização da rede de saúde que constitui um sistema único, bem como do êxito das ações que decorrem do regime de colaboração dos sistemas de ensino, conforme asseguram os artigos 198 e 211 , $1^{\circ}$, todos da CRFB/1988, mantendo, assim, a higidez do sistema a que visa alcançar o federalismo cooperativo, por meio do disciplinamento de matérias desse jaez, em leis nacionais, conforme discorre Odilon Cavallari de Olliveira (2008), que defende esse caminho constitucional para colmatação dessa lacuna:

Extrai-se, portanto, do Texto Constitucional de 1988 a acentuada preocupação com as finanças públicas, concernentemente a todas as fases do ciclo orçamentário e também do financeiro, alcançando inclusive os atos e procedimentos administrativos necessários para se atingir os objetivos visados, motivo pelo qual há na Constituição disposições relativas à gestão 
responsável (arts. 163 a 169), às licitações e contratações (arts. 22, XXVII, e 37, XXI), aos consórcios públicos (art. 241) e ao controle das finanças públicas (arts. 52, V, VI, VII e IX, 70 a 75, e 163).

Não há como esperar êxito do federalismo cooperativo num ambiente que não confira um padrão mínimo de funcionamento ao controle das finanças públicas, em que não haja a centralização das diretrizes desse controle, o que abre margem para que as instituições dos estados federados, tanto na execução das normas de finanças públicas quanto no controle da execução delas, ajam de forma discrepante, gerando desequilíbrio interno e externo, que onera a União e, consequentemente, os estados que não deram causa ao desequilíbrio das contas públicas.

Foi também pautado nas consequências diretas e nos reflexos que o processo de controle externo pode produzir na esfera de direitos subjetivos de terceiros, atingindo direitos fundamentais, como honra, patrimônio e liberdade, que o legislador incluiu o artigo 30 da LINDB, impondo às autoridades públicas - leia-se, também, os agentes controladores - o dever de atuar com vistas a aumentar a segurança jurídica na aplicação das normas, inclusive por meio da edição de regulamentos, súmulas administrativas e respostas a consultas.

Essa segurança jurídica, contudo, não se limita à vedação à aplicação retroativa de interpretação administrativa, até porque essa preocupação, por si só, não justificaria a inquietude dos subscritores e defensores das inovações, seja porque essa vertente da segurança jurídica já era expressamente prevista no artigo $2^{\circ}$, parágrafo único, inciso XIII da Lei n. 9.784/1999, de aplicação subsidiária ao processo de controle externo, seja porque da inobservância dela já fazia surgir o direito ao exercício da controlabilidade judicial dos atos emanados da esfera controladora externa.

Aliás, citando Celso Antônio Bandeira de Mello, Pelegrini (2014, p.61) aponta que o aludido autor enfatiza o critério formal, ao afirmar que a natureza administrativa da infração é reconhecida pela natureza da sanção, que, por sua vez, é reconhecida pela autoridade competente para impô-la, do que se extrai a distinção das sanções administravas das controladoras. 


\section{CONCLUSÃO}

Essas breves linhas se propõem a demonstrar que constitui elemento importante para o alcance da segurança jurídica a observância do disposto no caput do artigo 71da CRFB, que, ao dispor que ao "Tribunal de Contas compete", enunciou que a colegialidade judicante se desse por meio de um processo de controle externo, observando as garantias do devido processo legal, ainda que no bojo de "ajustamentos de gestão", por exemplo, garantindo a devida motivação e não deixando margem para dúvidas sobre a imparcialidade dos agentes que agem em nome dos órgãos de controle, em cada fase processual, nos moldes disciplinados, inclusive, no artigo $1^{\circ}, \S^{\circ}$, inciso I da Lei Orgânica do TCU, paradigma de funcionamento, donde também se extrai a independência entre as três funções processuais, tudo com vistas a minimizar a possibilidade de ocorrência de prejuízos anormais ou injustos resultantes do processo ou da conduta dos atores processuais, o que geraria o direito à compensação a que alude o artigo 27 da LINDB, podendo ensejar a responsabilidade objetiva do estado e, consequentemente, a subjetiva dos agentes públicos que derem causa ao dano, por dolo ou culpa.

Partindo disso, o artigo buscou trazer elementos que demonstram a necessidade de adoção de mecanismos institucionalizados capazes de resguardar a imparcialidade que deve pautar toda a marcha processual que culminar nas decisões, sancionadoras ou não, dado que o contrário pode vir a dar azo ao exercício da controlabilidade judicial dos atos emanados dos órgãos controladores externos, abrindo espaços, também, para riscos de fragilização da situação jurídico-funcional dos agentes públicos que intermedeiam a materialização da função de controle externo exercida pelos Tribunais de Contas, no exercício das competências estatuídas com maior largueza no artigo 71 da CRFB/88.

Extrai-se, por fim, de uma exegese do artigo 24, I, 73 c/c 96, I, "a", 75 e 163, V da CRFB/1988, que há parâmetro normativo-constitucional para a edição de uma lei nacional para regulamentar o processo de controle externo, o que garantiria a segurança jurídica no controle e higidez das finanças públicas, contribuindo, também, para o alcance dos fins a que busca alcançar o federalismo cooperativo. Adicionalmente, conclui-se que a inércia na elaboração da referida lei nacional 
constitui uma das causas da assimetria existente entre os 33 Tribunais de Contas do Brasil, mas que essa lacuna não constitui óbice intransponível à adoção de procedimentos uniformes para processualizar o exercício das competências institucionais estatuídas no art. 71 da CRFB/1988, pautados exatamente na persecução do princípio da simetria constitucional previsto no artigo 75 e na aplicação subsidiária dos demais ramos processuais.

Para além disso, o artigo possibilita constatar que um processo de controle externo hígido em todas as suas etapas é um instrumento capaz de minorar os efeitos decorrentes das fragilidades dos arranjos institucionais vigentes, dentre as quais a forma de ingresso dos integrantes da função judicante, a ausência do referido código nacional de processo de controle externo e da positivação constitucional expressa de independência entre as três funções processuais, que, como abordado, colocam diretamente em risco a independência na atuação dos Tribunais de Contas, pilar no qual se sustenta a regularidade de desempenho da função de controle, e não apenas da função de Controle Externo da Administração Pública.

Infere-se, por fim, que, agindo regularmente, passando do plano da normatividade constitucional para o da efetividade institucional, os Tribunais de Contas serão verdadeiramente reconhecidos como instituições controladoras indispensáveis à manutenção do Estado Nacional e Democrático de Direito, sem a presença dos quais estaria a sociedade suscetível ao enfrentamento de crises de instabilidade nos pilares nos quais se escora a estabilidade social, sendo descabidas, portanto, eventuais defesas de medidas que caminhem no sentido da fragilização dessa instituição de notável envergadura constitucional, fazendo-se necessário, entrementes, pelas razões exaustivamente expostas, o aperfeiçoamento do sistema vigente.

\section{REFERÊNCIAS}

ASSOCIAÇÃO DOS MEMBROS DOS TRIBUNAIS DE CONTAS DO BRASIL (ATRICON). Para brasileiros, Tribunais de Contas são essenciais no combate à corrupção e à ineficiência, revela pesquisa IBOPE/CNI. 2016. Disponível em: http://www.atricon.org.br/imprensa/destaque/para-brasileiros-tribunais-de-contassao-essenciais-no-combate-a-corrupcao-e-a-ineficiencia-revela-pesquisa-ibopecni/ Acesso em: 25 mar 2019. 
BRASIL. Constituição Federal de 1967. Constituição da República Federativa do Brasil. Brasília, 1967. Disponível em: http://www.planalto.gov.br/ccivil 03/Constituicao/Constitui\%C3\%A7ao67.htm>.

Acesso em: 24 abr 2019.

. Constituição Federal de 1988. Constituição da República Federativa do Brasil. Brasília, $1988 . \quad$ Disponível em: http://www.planalto.gov.br/ccivil 03/constituicao/constituicao.htm Acesso em: 24 abr 2019.

Decreto n. 5.687, de 31 de janeiro de 2006. Promulga a Convenção das Nações Unidas contra a Corrupção, adotada pela Assembleia-Geral das Nações Unidas em 31 de outubro de 2003 e assinada pelo Brasil em 9 de dezembro de 2003. 2006. Disponível em: http://www.planalto.gov.br/ccivil 03/ ato20042006/2006/decreto/d5687.htm Acesso em: 24 abr 2019.

. Lei n. 8.429, de 02 de junho de 1992. Dispõe sobre as sanções aplicáveis aos agentes públicos nos casos de enriquecimento ilícito no exercício de mandato, cargo, emprego ou função na administração pública direta, indireta ou fundacional e dá outras providências. 1992a. Disponível em: http://www.planalto.gov.br/ccivil 03/leis/L8429.htm Acesso em: 24 abr 2019.

. Lei n. 8.443, de 16 de julho de 1992. Dispõe sobre a Lei Orgânica do

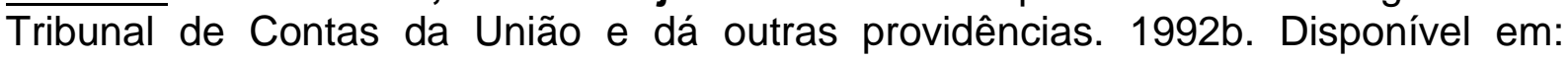
http://www.planalto.gov.br/ccivil 03/leis/L8443.htm Acesso em: 24 abr 2019.

. Supremo Tribunal Federal. MS 23.550-1DF, Rel. Originário Min. Marco Aurélio, pleno, DJU de 31 out. 2001. Disponível em: http://portal.stf.jus.br/processos/detalhe.asp?incidente=1781907. $>$ Acesso em: 30 jul. 2019.

ADI 5323. Relatora: Min. Rosa Weber. DJE no 89, divulgado em 30/04/2019. Disponível em: <http://stf.jus.br/portal/diarioJustica/> Acesso em: 18 jul. 2019. - Tribunal de Contas da União. Normas de Auditoria do Tribunal de Contas da União, Publicada em 05 de julho de 2011, revisão junho 2011. Disponível em: www.tcu.gov.gr. Acesso em: 24 abr 2019.

BRITTO, Carlos Ayres. O Regime Constitucional dos Tribunais de Contas. Belo Horizonte: Editora Fórum, Disponível em: <http://www.editoraforum.com.br/noticias/oregime-constitucional-dos-tribunais-de-contas-ayres-britto/> Acesso em: 16 jan. 2019. BUCCI, Maria Paula Dallari. O conceito de política pública em direito. In: BUCCI, Maria Paula Dallari (org.). Políticas públicas: reflexões sobre o conceito jurídico. Rio de Janeiro, 2006.

ESCRITÓRIO DAS NAÇÕES UNIDAS CONTRA DROGAS E CRIME (UNODC). Convenção das Nações Unidas Contra a Corrupção. 2003. Disponível em: https://www.unodc.org/documents/lpo- 
brazil//Topics corruption/Publicacoes/2007 UNCAC Port.pdf Acesso em: 06 mar 2019.

DICIO, Dicionário Online de Português. INTEGRADO. Porto: 7Graus, 2018. Disponível em: https://www.dicio.com.br/integrado/.> Acesso em: 30 jan. 2019.

INSTITUTO RUI BARBOSA (IRB). Normas Brasileiras de Auditoria do Setor Público (NBASP). 2015. Disponível em: <https://portal.tcu.gov.br/fiscalizacao-econtrole/auditoria/normas-brasileiras-de-auditoria-do-setor-publico-nbasp/.> Acesso em: 24 out. 2018.

JACOBY FERNANDES, Jorge Ulisses. Tribunais de Contas do Brasil: jurisdição e competência. 4. ed. revista, atualizada. e ampliada. Belo Horizonte: Fórum, 2016.

LOPES JUNIOR, Aury. Fundamentos do processo penal: introdução crítica. 3. ed. São Paulo: Saraiva, 2017.

OLIVEIRA, Odilon Cavallari de. Diante do princípio federativo, seria constitucional uma lei nacional de processo dos tribunais de contas? Revista do Tribunal de Contas da União Brasil, ano 40, número 113, setembro/dezembro 2008. Disponível em: $<$ https://portal.tcu.gov.br/biblioteca-digital/revista-do-tcu-n-113-set-dez-2008.htm>. Acesso em: 26 jan. 2019.

PELEGRINI, Marcia. A competência sancionatória do Tribunal de Contas: contornos constitucionais. Belo Horizonte: Fórum, 2014.

SPECK, Bruno Wilhelm. Inovação e rotina no Tribunal de Contas da União: o papel da instituição superior de controle financeiro no sistema político-administrativo do Brasil. São Paulo: Fundação Konrad Adenauer, 2000. 